\title{
Chapter 14 \\ Life Cycle Management Responsibilities and Procedures in the Value Chain
}

\author{
Fritz Balkau, Eskinder Demisse Gemechu, and Guido Sonnemann
}

\begin{abstract}
Product life cycles and companies' value chain dynamics now extend to far-away countries, linking a multitude of end-users with numerous upstream suppliers and manufacturers. The breadth of the sustainability issues of popular concern, together with the complex nature of supply chains from which they arise, leads to serious management challenges. These challenges have been met in different ways depending on the interests and the institutional context of the actors. Corporations are strongly focused on optimizing product performance through a reliance on life cycle assessment based procedures. Commodity sectors are often seeking harmonized sustainability performance across a broad geographical range. Management institutions and business associations are providing life cycle management frameworks for corporations, followed up with training, and further research into improved metrics. At regional level some efforts have been made to introduce life cycle approaches, e.g. sustainable procurement, but the formal application of structured life cycle management is not yet widespread. The different approaches taken by the above actors reflects not only their different situations, but also the lack of a clear universal framework for life cycle management and a more generalized toolbox that will support their sustainability ambitions throughout the value chain. Limitations of current life cycle assessment methodologies imply that not all sustainability challenges are addressed in a consistent manner.
\end{abstract}

Keywords Life cycle assessment • Life cycle management • Responsibilities

- Supply chain • Value chain

\footnotetext{
F. Balkau $(\bowtie)$

Sustainable Solutions, 4 rue le Regrattier, 75004 Paris, France

e-mail: fbalkau@gmail.com
}

E.D. Gemechu • G. Sonnemann

University of Bordeaux, ISM, UMR 5255, 33400 Talence, France

CNRS, ISM, UMR 5255, 33400 Talence, France 


\section{Introduction}

Product life cycles and companies' value chain dynamics are always complex. Value chains now extend to far-away countries, linking a multitude of end-users with numerous upstream suppliers and manufacturers. Production inefficiencies at each step rapidly cascade through these chains, leading to unwanted products and wastes accumulating along the way:

...only about $1 \%$ of all the materials mobilized to serve America are actually made into products still in use six months after sale, ... (Hawken et al. 1999)

Social conditions have gained greater visibility. The popular press throws a regular spotlight on deplorable labor practices and human rights conditions before a product even reaches the consumer. With these expanded notions, the environmental impacts have become more difficult to understand by the general public and many decision-makers. Our concerns have progressed from simple notions of waste and resource depletion to encompass also subtle effects of trace chemicals (e.g. endocrine disruptors) and the massive degradation of our life-support systems. There is much to do in response to these pressures, from improving the performance of individual products to a general overhaul of our entire production and consumption system. In both cases, we need a life-cycle approach to our management intervention if we are to do more than just tinker with the problem.

\section{Looking into the Life Cycle Management Agenda}

When referring to procedures within life cycle management (LCM), it is important to be clear about our propositions. There is an evolution in language that includes mention of life cycle, value chains, supply chains, materials cycles, circular flows and so on. In part this reflects the growth of life cycle type studies, processes and evaluations, but it soon spills over also into operational management concepts. Even the notion of 'life' of a material or product is not fixed. And if we are concerned with both upstream and downstream aspects of company activities we can no longer refer simply to 'supply chain', in which only the upstream focus is considered. In this paper we have chosen to refer to the 'value chain' since it covers multiple product life cycles of a company. Value chain can better include non-material and non-environmental values such as social appreciation and cost as well as management dimensions that are directly related to company activities and not to the engineering aspects of a product. All these are important considerations as the notion of sustainable consumption and production becomes more and more a question of operationalization in a business context.

So how can we manage the value chain from a sustainability perspective? The breadth of the issues of popular concern, together with the complex nature of the materials chains from which they arise, leads to a serious management issues (Balkau and Sonnemann 2011). As well as ensuring economic viability, managers 
need to take into account a host of externalities, many of them from outside the corporation. Attempts to link economic self-interest (i.e. efficiency gains) with these externalities has only been partially successful as some issues clearly represent a non-recoverable cost. It is easy to speak of the 'triple bottom line'; operationalizing it for extended value chains remains a challenge for individuals and enterprises alike.

A part of LCM is concerned with improving profitability of corporations. However, many LCM objectives are directly drawn from the sustainability agenda, i.e. building a better future for us all. While the main components - social, environmental and economic - are now universally accepted, the specific goals to be achieved within them are subject to wide interpretation. This is especially the case for the social components of labor practices, human rights and cultural and intellectual property. Even environmental standards vary widely.

The term life cycle management is currently applied to a wide variety of initiatives that show major differences in approach (Remmen et al. 2007). Objectives vary widely, from optimizing a product to saving the planet. Much of LCM can be seen as a fusion of supply chain management (SCM) and extended producer responsibility (EPR), using life cycle assessment (LCA) and other assessments as input. But while LCA and a variety of corporate management tools have been codified, LCM itself is still subject to varying definitions, interpretations and practices according to the viewpoints and objectives of the principal actors (Seuring 2004). It does not help that the notion of sustainable development is itself evolving, resulting in shifting targets for any management endeavor.

In fact, we are seeing several approaches to LCM evolving side by side. Thus companies unilaterally managing the upstream dimension of their supply lines work in parallel with sector-wide initiatives that operate under an agreed chain-of-custody framework that includes codes of conduct, independent review and sanctions for non-performance. Some progressive companies do both simultaneously, albeit not always for the same products.

While we observe that LCM has already been extensively used, closer examination reveals that many of these applications lack the rigor that is a feature of LCA itself. Supply chains are kept deliberately short to enable more effective management control, and objectives are reduced to a few parameters that reflect current corporate viewpoints rather than the aggregate needs of the environment. A common deficiency of many LCM exercises is that they often overlook the importance of the downstream consumer where much of the sustainability impact actually occurs. In short, for practical reasons much LCM lacks both depth and breadth.

\section{Corporate Practice in Life Cycle Management}

Much effort by corporations and supporting institutions has gone into translating the results of LCA into actual management interventions of their value chains (Remmen et al. 2007). Classic examples include the LCM practice of major 
manufacturing companies like $3 \mathrm{M}$ (2015) as well as of global retailers such as Walmart (2015). Their approaches show many similarities, but also some differences in the way they are managed. While the retailers see LCM predominantly through the prism of supply chain management, the manufacturers are often more focused on using LCM internally to improve product development and reduce production costs. In such cases internal co-ordination and collaboration between different parts of the organization becomes important. The breadth of this collaboration will depend on the objectives of the LCM exercise, i.e. whether it is primarily intended to influence product development or more aimed at addressing external sustainability issues in the supply chain. Like most management exercises, a mainstreaming of LCM in a corporation under the direction of the CEO (Chief Executive Officer) will be more successful than creating a special 'add-on' LCM service. The latter faces too many obstacles of acceptance by the existing mainstream departments.

For the retailers, it is vital to bring the entire upstream supply chain into LCM exercise as this is where many of the major environmental and social impacts need to be addressed. Thus IKEA's Code of Conduct (IKEA 2012) specifies minimum requirements on its 1600 suppliers covering social, environmental and labor-related conditions. While the code of conduct provides a clear statement of objectives, compliance is unlikely to be achieved automatically; much work is needed with supply chain actors to inform, explain, educate and train key partners along the chain. Some 'recognition' instruments can be used to identify reliable suppliers e.g. certification of ISO 14001. While major companies do work directly with their suppliers to facilitate compliance with company requirements, it is not well documented how far up the supply chain the influence is actually exerted.

TRUCOST has undertaken surveys of how many companies publicly report on their suppliers' impacts. TRUCOST found that of the environmental damage caused by the world's largest 3,000 companies annually, $49 \%$ comes from within supply chains (Salo 2015).

Some companies, such as Puma, are actively collecting supply chain environmental performance information for use in their business decisionmaking. Puma, part of the PPR Group, conducted a detailed analysis of the environmental impacts of its operations and supply chain. Only $6 \%$ of the impacts come from Puma's offices, warehouses, stores and logistics. The rest come from its supply chain, more than half from the production of raw materials for manufacture. The findings were used by Puma to review where its raw materials came from, and what materials to source at all.

Direct suppliers are the most visible. But managing the suppliers of the suppliers remains a complicated exercise for individual companies. Traditionally corporations simply relied on contracts with its supply chain. An earlier study by Seuring 
and Goldbach (2002) showed that the collective negotiation model for sustainable supply chain management is more successful than a command and control approach.

In some cases, the direction of the coordination may also need to be reversed. Suppliers with a number of different clients may find that the latters' demands are not compatible, or are inconsistent in other ways. This has led to some collective arrangements where several clients and their different suppliers agree on a common agenda, and perhaps also a common communication and certification system.

LCM involving sub-contracting and global supply chain management may face serious political hurdles and trade barriers. Sustainability requirements on suppliers may not be well accepted by foreign governments who see this as interference in their national affairs and an unwanted application of western environmental standards. The political disputes over products manufactured by child labor, and/or subject to lax or unenforced safety and environmental standards have been rumbling on in global trade negotiations for many years. Fair-trade labels are not seen the same way from opposite ends of the supply chain, and LCM has to be sensitive to such issues. While company requirements on their suppliers may appear to be simple contract arrangements between companies, the issues easily spill over into political rancor and trade reprisals. As well, the WTO has a general policy to avoid environmental conditionality in trade arrangements.

Management techniques will depend on which parts of the value chain are included in the LCM exercise. There is a gradual movement, often spurred by legislation, to consider downstream issues of consumer protection, efficiency in use and end-of-life disposal. Managing the downstream parts of the life cycle requires different procedures and skills because the consumer needs to be persuaded rather than commanded into conformity with the LCM objectives. While shaping consumer behavior remains a delicate marketing issue, some corporations are already reaching out to their clients about the appropriate use of their products. The example of Unilever is shown below (Unilever 2015). Unilever's sustainability strategy addresses environmental impacts across the value chain.

"Our commitment to reduced environmental impact extends right across our value chain - i.e. from the sourcing of raw materials through our own production and distribution to consumer use and eventual disposal of residual packaging. Consumer use accounts for around $70 \%$ of our greenhouse gas footprint. Engaging consumers .... will be key to achieving our vision. Metrics for our four priority environmental impact areas across the value chain include greenhouse gas (GHG) emissions, water, waste, and sustainable sourcing. These metrics are designed to measure the impacts of our products when used by consumers, such as grams of greenhouse gas per single usage occasion. During 2009 around 1500 products were assessed to allow us to understand their water, waste and GHG impacts in 14 of our largest markets. In 2009 we also started to develop a set of metrics covering social impacts. For .. brands with social missions, the metrics seek to measure the benefits they bring to society. In 2010, Lifebuoy used the new metrics, helping track the impact of Lifebuoy programmes on hand washing behaviours over a five-year period".

We are still a long way from a universal application of his concept, even if some examples are well documented. The notion of downstream LCM is linked also to 
the idea of Product Service Systems where the manufacturer has replaced a product by a service, as for example in renting products instead of selling them (the story of Interface, SafetyKleen and others).

\section{Collective Model for Life Cycle Management}

An alternative LCM model with good success is based on a formal collaboration that binds the principal value chain stakeholders through a common, agreed code. The Code specifies objectives, governance, partner responsibilities and a monitoring and reporting mechanism. This model is especially suited for sector-wide LCM programs that address system issues, with useful examples found in forest, fisheries, food and chemicals stewardship. While similar in most aspects in addressing supply chain issues, many of these programs do not necessarily label themselves as LCM. A particular feature is that many of them are not even based on formal LCA as a precursor; they address directly well-understood concerns of sustainability or of safety.

Several initiatives in the natural resource exploitation area have developed sophisticated LCM procedures based on agreed objectives. The FSC (Forest Stewardship Council) (https://ic.fsc.org/) and MSC (Marine Stewardship Council) (www.msc. org/) pioneered this approach using a formal code of operation and on-going monitoring and review. Company operations are independently verified and certified as code compliant, with public reporting on key performance indicators. Stakeholders have extensive opportunities to provide input via electronic means, in workshops and in governance meetings. The supply chain extends from producer through distributors to retailers and eventually down to the consumer who is able to exercise a choice based on sustainability criteria specified on the product label. 'Management' thus occurs at several decentralized points in this chain in line with an agreed collaborative charter. It remains that while the 'production' parts of the supply chain are well controlled, the downstream consumer end is weakly addressed, being reduced to a simple label on the product (fish, timber). Like much of LCM, there is no advice concerning the use of the product and how to deal with consumer waste at end of product life.

In addition to the above, a range of other initiatives can be found concerning consumer products aimed at fair trade, organic produce and the like. Many rely on a product label that identifies a particular environmental or social quality; however the management of the quality assurance behind the label is an unknown quantity. Third party certification is sometimes used, but much organic produce, for example, seems to have little rigorous LCM behind it (or LCA ahead of it).

In terms of life cycle reach the most complete LCM instrument and the most rigorous structure is without doubt the International Cyanide Management Code (www.cyanidecode.org) that aims to ensure safe and environmentally sound handling and use of this toxic chemical in the gold mining industry as shown below.

The International Cyanide Management Code was developed to help gold producers operate in ways that prevent risks to workers, the public and the environment at all points of the product's life. The Code requires signatory companies to apply 
strict rules, both technical and procedural, for handling cyanide along its life cycle. Signatory companies are regularly third-party audited and certified, with mandatory incident reporting. Reports are publicly available. An independent institute administers the code. A particular feature of the Code is its total value chain reach: even the upstream chemical manufacturers, suppliers and transporters must comply with the Code requirements before the end-user mining company can purchase the substance. The Code is sharply focused; it deliberately addresses only a limited number of sustainability objectives concerned with cyanide toxicity; it is not a 'do everything' code. Code membership brings operational benefits and public relations and financing advantages. A number of financing institutions and planning bodies now require code compliance before they deal with gold mining companies, while companies regularly mention the code in their public communications.

The code concept has also been used in related sectors, such as by diamond (the so-called Kimberley process (www.kimberleyprocess.com/) and jewelry suppliers (www.responsiblejewellery.com/) who have put in place a 'chain of custody' control of operations by their members. In each case, the entire supply chain is subject to the sustainability requirements of the end-user - pollution, risks, social conditions, etc. The selection of sustainability criteria varies among the different codes, usually incorporating a strong emphasis on social issues (e.g. Kimberley) as well as pollution-type factors (e.g. cyanide code). It may be criticized that these voluntary codes only bind their members. In the case of the cyanide code, over half of world gold production is now code compliant, an achievement that few other activity sectors can claim. In any case, a non-regulatory character is a feature of nearly all LCM exercises.

The usefulness of sector-wide agreements such as the above becomes clear when we consider LCM from a supplier perspective. Suppliers often have many different clients. It would be overly burdensome if each client were to impose its own sustainability or quality standard on the supplier who is then not only faced with additional administration but also a fragmentation of product quality requirements. Several initiatives of sector-wide LCM are know in, for example, the international textile trade, to coordinate diverse LCM requirements. These initiatives often focus on social and labor issues, less so on environmental agenda although examples of this are known also.

In some instances, government participation is necessary to ensure sufficient management buy-in. The UK's Defra, for example, sponsored an LCM initiative in the clothing sector to ensure better alignment with social and environmental expectations.

The initiative has voluntary participation from all major stakeholder groups implicated in the sustainable management of clothing, including at the supply end in Asia. The structure is less rigid than the codes of ICMI or FSC; however, it has the advantage of handling a broader range of sustainability issues (Fig. 14.1).

Another useful example comes from the electronics industry. The GeSI initiative (GeSI 2015) brings telecoms, appliance manufacturers and service companies together in an effort to improve traceability of materials used in manufacture of appliances (as well as actual improved environmental and social performance along 


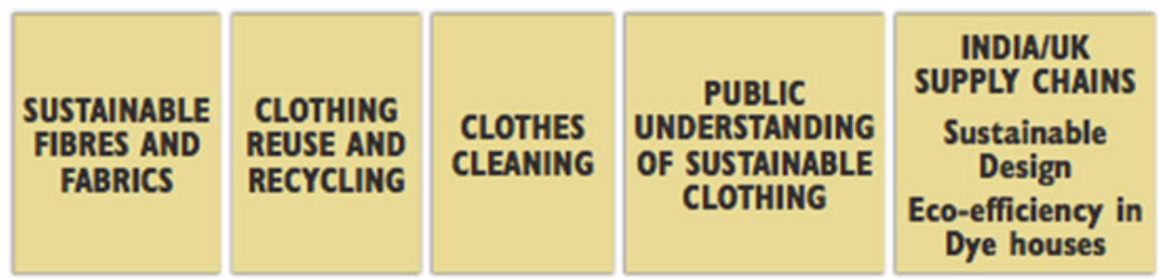

Fig. 14.1 The LCM initiative in the clothing sector (Source: Defra 2011)

the supply chain). Among other objectives it aims to improve environmental performance and resource efficiency and support sustainable supply chain practices. Of direct relevance to LCM is the conflict-free smelter initiative incorporating a labor code, certification, inspections and compliance listing. Further along the chain, manufacturers are encouraged to prefer purchasing from conflict-free smelters.

Table 14.1 Management instruments used in collaborative schemes

Stakeholder dialogue/conference

Agreement on criteria, objectives, targets

Code of conduct for members

Technical or procedural guidelines/codes

Chain of custody linkages along the value chain

Training for compliance initiatives

Third party audits

Certification of compliance

Non-compliance reporting

Transparent reporting

Product labels

Customer use advice

Membership-based structure

Secretariat to administer, monitor, review

Compliance may be required by planning/financial institutions

Compatible with supply chain management practices, eco-labels, environmental audits, sustainable procurement

The GeSI initiative is noteworthy for three aspects: (i) it is sector-wide and engages a large number of companies, (ii) it spans most of the value chain from mining of resources to consumer use and end-of-life recycling, and (iii) it includes multiple sustainability criteria from labor/social to energy to waste. GeSI has partnered with non-industry stakeholders like business groups, international institutions and NGOs.

We can summarize some of the management instruments used at various times in these collaborative schemes as per Table 14.1.

Each of the above collaborative initiatives has its particular origins. Each has taken an independent path to arrive at similar end-point where the collaboration is 
subject to an agreed framework and action plan. There is, however, no standardization of this approach that gives guidance to future initiatives elsewhere and in other sectors. An attempt to provide such a framework through ISEAL attempted to federate individual initiatives and to facilitate experience sharing. So far ISEAL regroups over 20 members (Fig. 14.2) mostly ones concerned with ethical and social issues surrounding resource exploitation (ISEAL 2015).

While obviously compatible with conventional LCM ideas, some of the collaborative initiatives may operate under other names such as SSCM, SMM, material management and so on. The diversity of nomenclature is perhaps one of the consequences of a lack of clear, formal and universally accepted framework of LCM.

\section{Life Cycle Management and Business Organizations}

Due to their influence over corporate management practice, it is useful to review also the role of management institutions and business associations in improving value chain performance. The peak business body WBCSD (www.wbcsd.org), while broadly endorsing a life cycle management approach, is concentrating on

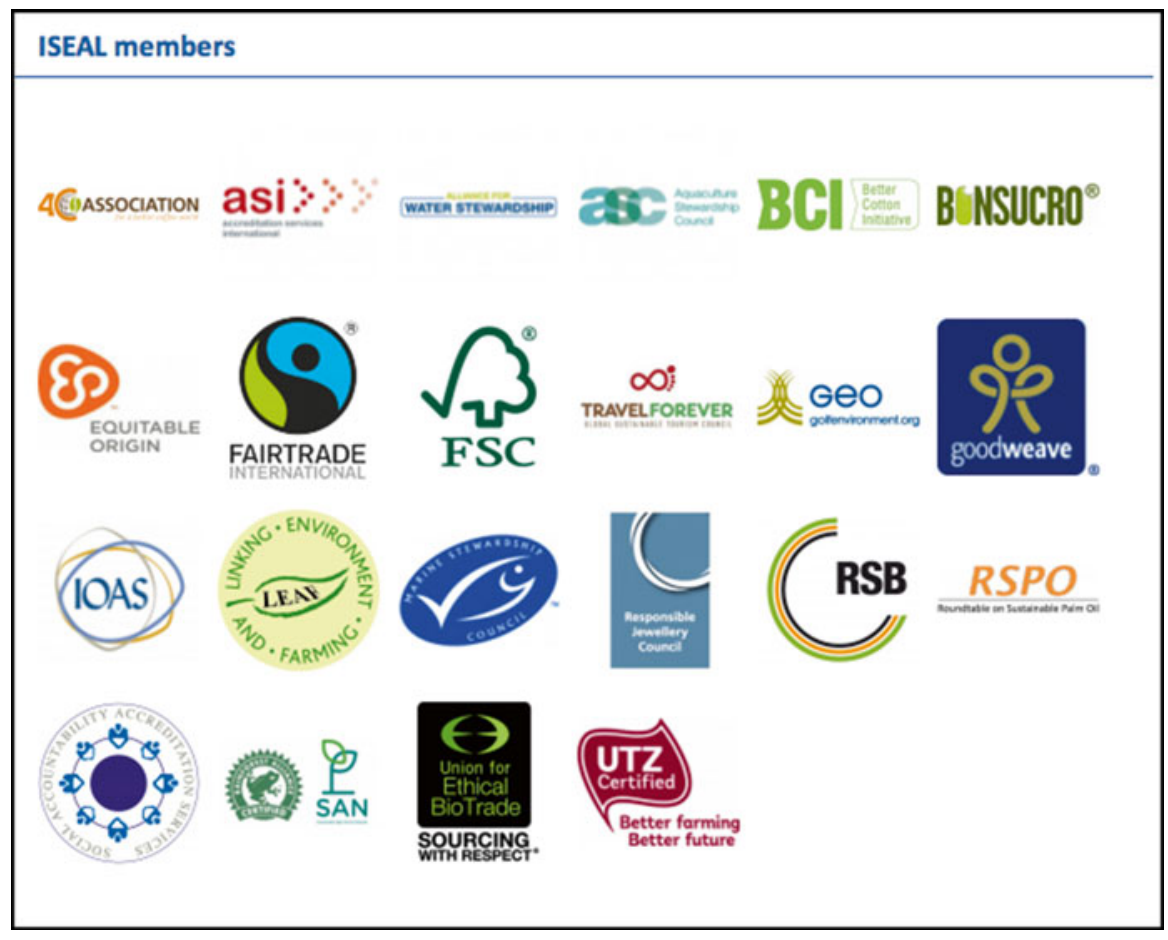

Fig. 14.2 ISEAL members (ISEAL 2015) 
improving the underlying metrics as, for example, practical materials accounting procedures.

This concern with metrics is also a preoccupation of other business groups, many of which have put substantial resources into developing appropriate measurement and assessment techniques for common use. ICMM (International Council for Mining and Metals) (www.icmm.com), for example, is a long-standing partner in the UNEP/SETAC Life Cycle Initiative. ICMM has been advocating a deeper use of 'sustainable materials management' (SMM) thinking by minerals companies.

This direction is echoed by the Australian government and the Minerals Council of Australian (MCA) in their advice to companies (Commonwealth of Australia 2006). The reach of the approach (up-stream suppliers to end-users), the breadth of sustainability objectives, its basis in scientific assessment, the range of management instruments to employ and the upstream/downstream multi-stakeholder involvement make these recommendations true LCM under another name (see Table 14.2, source ICMM (2006)). The value of these advisory initiatives is substantial because the advocated management framework ensures a coherent approach to LCM across

Table 14.2 Elements of successful implementation and integration - from ICMM (2006)

\begin{tabular}{|c|c|}
\hline \multirow[t]{3}{*}{ Strategy } & $\begin{array}{l}\text { Strong leadership for the initiative - champions in key business units, clear } \\
\text { direction from the CEO and corporate action plan on sustainable development }\end{array}$ \\
\hline & $\begin{array}{l}\text { Clear understanding and awareness throughout the company of the business } \\
\text { value }\end{array}$ \\
\hline & $\begin{array}{l}\text { A well-articulated policy or vision statement that addresses or include materials } \\
\text { stewardship }\end{array}$ \\
\hline \multirow[t]{2}{*}{ Systems } & $\begin{array}{l}\text { Link to existing management systems, such as ISO 14001, as a means for issue } \\
\text { identification, impact assessment, target setting and continual improvement }\end{array}$ \\
\hline & $\begin{array}{l}\text { Integrate materials stewardship into appropriate business planning processes and } \\
\text { reward or incentive systems }\end{array}$ \\
\hline \multirow[t]{4}{*}{ Programs } & $\begin{array}{l}\text { Training and awareness raising programs for business units and departments } \\
\text { where skills need to be developed - for instance on life cycle thinking, risk } \\
\text { assessment, material flows, knowledge of environmental issues across the life } \\
\text { cycle and in end-use markets, regulatory environmental trends }\end{array}$ \\
\hline & $\begin{array}{l}\text { Engagement programs - with suppliers, downstream manufacturers, users, } \\
\text { recyclers and other stakeholders to identify opportunities for improving } \\
\text { production, manufacture, use and end-of-life management of materials }\end{array}$ \\
\hline & $\begin{array}{l}\text { Measuring and reporting programs - develop targets and indicators for materials } \\
\text { stewardship and report publicly to enhance reputation and accountability }\end{array}$ \\
\hline & $\begin{array}{l}\text { Commodity specific stewardship plans - develop in conjunction with other actors } \\
\text { in the value chain }\end{array}$ \\
\hline Tools & $\begin{array}{l}\text { Assessment and decision support tools - eco-efficiency, design-for-environment, } \\
\text { life cycle assessment and thinking, risk assessment and management, materials } \\
\text { flow analysis }\end{array}$ \\
\hline \multirow[t]{2}{*}{$\begin{array}{l}\text { Data and } \\
\text { other } \\
\text { information }\end{array}$} & $\begin{array}{l}\text { Life cycle inventories, risk assessments (environmental, health and safety), } \\
\text { material flow analysis (common templates for compiling and communicating } \\
\text { resource flows), recycling rates data, use/application data }\end{array}$ \\
\hline & Organizations and contacts along the value chain \\
\hline
\end{tabular}


an entire industry. A sector-wide approach to LCM ensures a level playing field for companies and gradually moves to a more widespread adoption of the procedures.

Other sector associations are also recommending LCM approaches to their members.

The chemicals sector has also acknowledged the importance of managing value chain issues. ICCA's 2006 Responsible Care Global Charter (www.icca-chem.org/) states that "... member companies and associations commit to promoting the Responsible Care ethic, principles and practices along their own value chains ... and to ... develop and share best practices through mutual assistance, and to ... work in partnership with upstream suppliers and downstream chemical users to collaborate on improved processes for the safe and effective uses of chemicals". ICCA organizes workshops and produces guidance publications to assist companies to implement these principles.

The International Solid Waste Association (ISWA) (www.iswa.org) published already in 2002 a forward-looking 10-year Perspective paper (ISWA 2002) advocating a holistic approach to waste management based on more complete consideration of the life cycle of materials that ultimately become waste. According to ISWA “... there is a need for a new approach. The focus must be upon the whole product life cycle and not only on the waste phase of products, substances and materials. Important decisions in relation to the amount of waste generated are taken both at the concept and design stage and further on during the production process. There is a need for dematerialization of the economic process..." Some of ISWA's workshops and documents are aimed at helping members move in this direction.

Some sector programs run in parallel with company initiatives. Thus AISE is encouraging a better use of its members' products (detergents) across their life cycle (AISE 2015), while Unilever is pursuing its own initiative to encourage clients to use less water and energy in the wash cycle (Fig. 14.3).

The frameworks developed by sector organizations are often the basis for LCM implementation by individual companies. Corporate members of FSC, MSC, ICCA, etc. frequently make reference in their stewardship and CSR (Corporate Social Responsibility) programs of their membership of these bodies, and the

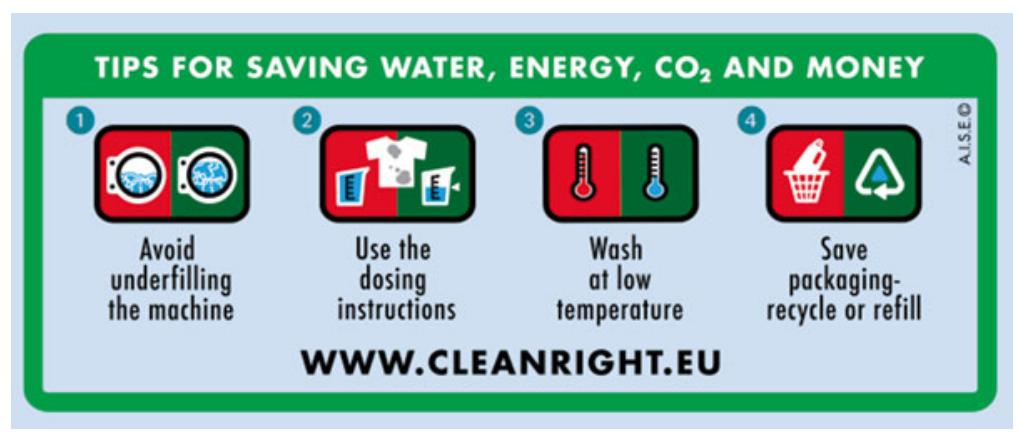

Fig. 14.3 Cleanright best use tips (Source: AISE 2015) 
compliance with the relevant codes, as well as conformity with independent initiatives such as GRI and Global Compact (see below).

Independent institutions are also supporting LCM through advice, training and sometimes through formal procedures. A good example of the latter is the Global Reporting Initiative (GRI) (www.globalreporting.org). The GRI Board of Directors identified disclosure on sustainability issues across the supply chain as a revision priority based on feedback from its committees and the wider GRI network. While GRI is not itself undertaking LCM, the increased transparency of individual company activities leads to greater management attention to the corporation's impacts along the value chain, eventually resulting in actual LCM oriented management interventions to improve value chain performance.

The Global Compact (www.unglobalcompact.org/) brings major corporations around a number of agreed sustainability principles. The GC Toolkit contains relevant instruments required for an application of life cycle management approaches, from assessment techniques to value chain interventions such as SCM and EPR.

There is also a role for policy intervention, beyond simply encouraging information and training. An in-depth review by the OECD titled "Sustainable Materials Management - Making Better Use of Resources" (OECD 2012) explores a set of policy principles for SMM application, examines how to set and use targets and analyses case studies from member countries. In this publication, SMM is closely aligned with LCM and explores the subsidiary instruments that make it function.

\section{Life Cycle Management in Regional Development}

LCM is not limited to corporate activity; it is an important concept at regional level where we have substantial resource and product flows, major infrastructure developments and important issues of social and human development. Many regional administrations have formally adopted sustainability objectives and are already undertaking footprint studies and ecological assessments. Life cycle ideas are creeping into individual programs and operations. But there is as yet little visibility of formal LCM approaches in most administrations, especially when confronted with long-term issues and complex material flows. This is not to say that LCM in not relevant, rather its use has not yet filtered down to regional administrators in a major way.

Nevertheless, some initiatives are already in this direction. Sustainable public procurement has become more evident in municipalities, although mostly without the technical backup in assessment. Nor do these programs actively "manage" the products they are purchasing - they are more of a 'buy/not buy' nature that sends relatively weak signals through the supply chain.

Thus while the Province of Nova Scotia has a sustainable procurement requirement under legislation, there is not a strong administrative capability to make it function effectively. A recent study in Canada found that supplier engagement was weak in most sustainable procurement programs at provincial level (Reeve 2012). 
The OECD, UNEP and the World Bank are now undertaking a programme of studies, workshops and publications to improve the quality of public procurement to boost national and regional economic progress. The sustainability dimension is included in this work.

Some states regulate ostensibly for life cycle objectives, as for example in California.

California's Green Chemistry Initiative 2012 (GCI) is a new law to regulate toxic chemicals in consumer products. The law incorporates a life cycle "alternatives analysis" to evaluate alternatives during their manufacture, in use and at disposal. Based on the evaluation, the state may restrict or ban the use of chemicals of concern.

Materials flow studies are now of increasing interest to public authorities, as is the use of footprint studies to better understand the regional sustainability dynamics. The OECD Environment strategy for the first decade of the twenty-first century (OECD 2001) outlined the need for governments to look for integrated management solutions that link resource use and prevention of waste into a coherent policy approach, such as the one embodied in the sustainable materials management (SMM) paradigm. The recent OECD report on SMM (OECD 2012) is directly aimed at clarifying the policy measures that improve the efficiency of materials flows at national and regional levels. But while useful in identifying national case studies, the policy recommendations sometimes seem rather remote from on the ground life cycle considerations.

The recent series of summer schools held by the University of Salento was directly aimed at exploring the application of life cycle approaches to sustainable regional development (www.lcss.unisalento.it/). This initiative has now been expanded into a publications project to illustrate how LCM techniques can be applied to regional planning, resource management, infrastructure, industrial development and environment protection.

But there is also the question of how LCA and LCM techniques can be further adapted to serve the special needs of these institutions and the administrators that would use these techniques.

\section{Link with Other Sustainability Management Initiatives}

LCM has to be seen also in the context of other resource management concepts as most of these have their roots in some form of life cycle thinking, and many of them advocate a particular management approach. Concepts of circular economy, industrial ecology, 3R, cradle to grave, etc. have been around for many years (Fig. 14.4). 


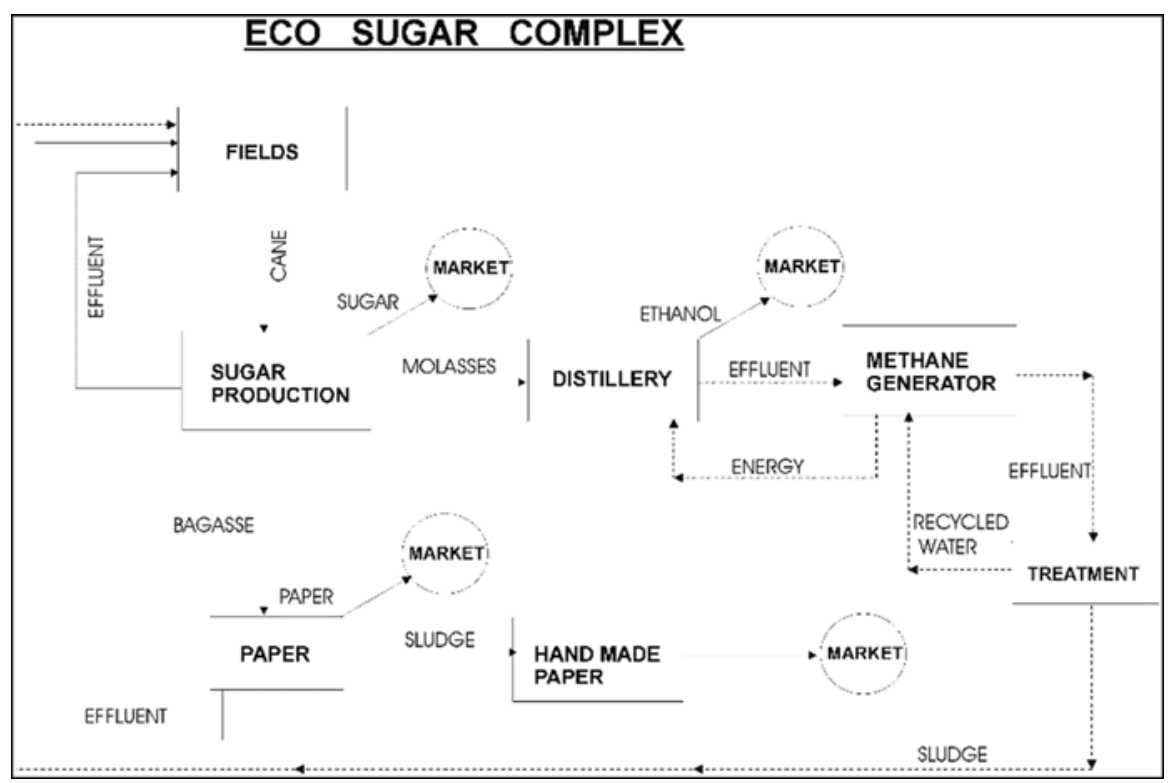

Fig. 14.4 Opportunities for LCM in a circular, life cycle, industrial ecology, 3R model for industrial production (Source: UNEP)

Life cycle in their conception, they are usually presented in materials flow rather than management terms and have their main impact on LCM objectives rather than on the management processes used. Conversely, the various programs on human rights and social conditions are not especially focused on a value chain approach but their objectives can still be taken into account in LCM applications. Finally, it is useful to try to link the downstream dimension of LCM with various 'consumption side' programs in the UN system, with green purchasing initiatives, PSS ideas and EPR for producers and retailers. Many of the solutions they propose can be more easily operationalized through LCM than on a stand-alone basis.

The extension of LCM into the downstream consumption area presents particular challenges, however this is precisely where much of the impact, and hence the real need, often lies. For many appliances and for buildings, for example, over $80 \%$ of energy use, and much materials consumption occurs during use. In the food cycle, end-point cooking is the most energy-demanding step. We already saw above the attempts by the detergent industry to address this point. Overall, LCM's reach so far into the downstream parts of the value chain can best be described as timid. Effective management action will no doubt need new partnerships with public policy institutions, governments and consumer organizations, but it cannot deny that this is an important area to address.

On the manufacturing side the concepts of cleaner production, eco-efficiency, green productivity and 'pollution prevention pays' have been adopted in many places, often incorporating recommendations for management that can be 
incorporated into LCM procedures (audits, materials flows, partnership-building ...). Many useful solutions have come from these concepts especially in major corporations that have the management strength to operationalize them.

It is in organizational frameworks that LCM finds its closest 'management' allies. The EMS framework of ISO 14001 is ideally suited to incorporate a value chain version of sustainability management. Corporate Social Responsibility (CSR), although not itself standardized, can also provide a framework for those LCM objectives related to social, human rights and labor issues. Management constructs like SCM and EPR underlie much of the life cycle 'management' methodology. And it hardly needs pointing out that the panoply of standardized (or not) assessment tools based around ISO 14040 series (among others) is what underpins LCM in the first place.

Many of the above management tools have tended to be used individually. LCM incorporates them into larger framework, adding, where needed, procedures such as product service systems (PSS), eco-design, eco-labeling, risk management and so on.

It is also evident that LCM in its attempt to influence the value chain of materials and products needs to find an accommodation with other management regimes, ranging from the WTO position on environmental condition in trade, the demands of future climate agreements, to the EU and OECD directives on chemicals management (e.g. REACH). Some of these have a certain value chain influence themselves that can be 'captured' by LCM.

At the policy level we have seen how SMM adopts the same value chain perspective as LCM.

As the building of stakeholder relations is at the core of successful LCM (whether internal or with external partners), the management of key player identification, communication, transparency and trust building is at the heart of the exercise. Coercive management models can have only limited application in a value chain. LCM can usefully learn from certain business sectors that have extensive experience in using such partnership techniques. Thus the toolkit developed by ICMM for successful community stakeholder building would be useful also in guiding LCM in other sectors.

Inevitably LCM, like many other areas of decision-making, will rely on thirdparty information, criteria and standards as a basis of its action. Its sustainability objectives are commonly based on international codes of practice and a variety of standards, whether ISO or other. In some cases work with, or endorsement by, major respected international NGOs will give credibility to the LCM exercise. But major corporations also adopt their own independent objectives on, for example, embedded energy or water use, recyclability and chemical composition. The use of third party standards and certification puts an extra dimension on the LC management exercise with which practitioners may be unfamiliar.

LCM is not the only sustainability game in town. In the end, LCM has to interface with the operational level to parallel initiatives and concepts. There can be no single universally valid technique because circumstances and objectives can be so diverse. But it does suggest that LCM should at certain moments be seen as a concept rather 
than a fixed technique, to be in turn the umbrella or the tool, as circumstances dictate. LCM's contribution will always be to propose an intervention strategy across the value chain reach of whatever is under consideration, whether it be a product (e.g. a detergent) or a procedure. (e.g. procurement).

\section{Summary and Conclusions}

The complex world of product life cycles and companies' value chain dynamics in our material world is mostly hidden from view. The complexity of addressing an extensive network of value chain stakeholders, coupled with the multiple criteria in the sustainable development agenda, means that a rigorous 'total life-cycle' management is almost impossible. A number most LCM initiatives are selective, focusing on only a limited number of steps and a selected few sustainability criteria. Realistic scoping is thus an important prerequisite to success. Within these limitations a number of different approaches to LCM are being pursued.

The success of any LCM exercise depends greatly on its objectives, how it is conceived and on who and what is included. For corporations focused on their products, the objectives will not be the same as for public institutions interested in optimizing the system as a whole. It follows that the methodologies and tools will not be identical. Thus collective code-based LCM is often interested in a global improvement in certain common issues such as social and labor conditions. Their methods include a big dose of multi-stakeholder building, often reaching down to their consumer base, plus transparency and communication. Individual manufacturing companies are more focused on using LCM to improve environmental performance of their products through reducing wastes, enhancing technologies, creating new markets and reducing liabilities. Much of their methodology is applied in-house although supplier engagement is necessarily a part of the exercise. Big retailers are interested in a positive profile for their products with consumers, and thus reach deep into their supply chain to try to achieve this. Few of the above have yet put downstream consumers, product effectiveness and end-of-life issues as mainstream components in their LCM exercises to the same extent as their focus on materials and social content. As a general statement, we can say that LCM has found more application in product enhancement than in systems optimization.

The public policy interface with LCM is still relatively undeveloped. There are many reasons for this, including political and short-term economic factors. But a major barrier is lack of appreciation by regional and national administrators of how LCM techniques could improve their program delivery. The currently inefficient use of sustainable public procurement is one example of this. This problem is exacerbated by the fact that many life cycle instruments are poorly suited for use at this level, either being too complex to use, or by not sufficiently incorporating some of the sustainability criteria that preoccupy the regions. It is also true that regulatory procedures often lack the flexibility to incorporate life cycle instruments due to the 
compartmentalized way, in which regulations are often developed. Further work by OECD and other institutions may help to break down these barriers and encourage a more comprehensive and less sectoral approach to sustainable materials management (SMM) and the like.

The varying interests of the major players mean that we can see several parallel strands of LCM being pursued, sometimes masquerading under other names. This parallelism arises from independent but converging programs. The visible UNEP SETAC Initiative with its past work on LCM was heavily influenced by the experience and viewpoints of the LCA community. The sector programs arose out of a need to address controversial sustainability issues that could not be resolved unilaterally such as overfishing, forest depletion and cyanide accidents. The SMM work sprang from the understanding by sector associations and governments that the issue of advanced waste management through resource stewardship had to be tackled at a level higher than single companies. Even earlier, the use of sustainable supply chain management arose from a need to reduce corporate liability for actions of environmentally unscrupulous suppliers and contractors. Sustainable procurement was seen as one of the immediate concrete actions that could be taken by institutions to implement Agenda 21. The various management operations under the above have some common elements but also some differences. The cooperative mechanisms may for example not rely on LCA as a basis of action. But it is also notable that the language and definitions of the theoretical constructs vary significantly, and there are a few human contact points where exchange of experience takes place. The LCM family is still very diverse, and its management approaches show significant differences.

In the above context, a comment can also be made about the adequacy of current assessment techniques as a basis for LCM. We noted above that LCA, while useful for resource flows, environmental impacts and cost evaluations, does not provide adequate input on management related parameters along the whole value chain of a company. Thus it gives too little information about the key (management) players actually found along the value chain who will have their part to play in effective LCM coalitions. Nor does LCA yet comprehensively evaluate a number of important sustainability criteria such as biodiversity, social conditions or trade impacts. Without such enhancements in the assessment phase, the management operations are handicapped in their ability to deal with a significant number of sustainability issues. Without such enhancements with regard to considering these criteria, LCM will continue to rely on a particular view with regard to sustainable consumption and production as well as some level of intuition and individuals' subjective understandings as much as hard data.

Overall, there remain significant challenges to a more rigorous approach to LCM at all levels. For the moment LCM remains more a management art than science, trying to bridge the gap between hard data and intuitive decision-making. Promising work in bringing more science in this field has been done for instance by Morel (2014). This type of work needs to continue and to include also management responsibilities in the products' life cycles and companies' value chains. 
Open Access This chapter is distributed under the terms of the Creative Commons Attribution Noncommercial License, which permits any noncommercial use, distribution, and reproduction in any medium, provided the original author(s) and source are credited.

\section{References}

3 M (2015) 3 M sustainability. Retrieved March 15, 2015, from http://www.3m.com/3M/en_US/ sustainability-us/industry-solutions/

AISE (2015) Consumer activities. Retrieved March 10, 2015, from http://www.aise.eu/ouractivities/information-to-end-users/consumer-activities.aspx

Balkau F, Sonnemann G (2011) Addressing sustainability issues through enhanced supply chain management (chapter 18). In: Renko S (ed) Supply chain management - new perspectives, Industrial engineering and management. InTech, Rijeka. doi:10.5772/799

Commonwealth of Australia (2006) Stewardship - leading practice sustainable development program for the mining industry. Retrieved from www.minerals.org.au/file_upload/files/resources/ enduring_value/stewardship.pdf

Defra (2011) Sustainable clothing roadmap: progress report 2011. Retrieved from https://www. gov.uk/government/publications/sustainable-clothing-roadmap-progress-report-2011

GeSI (2015) Global e-sustainability initiative. http://gesi.org/

Hawken P, Lovins AB, Lovins LH (1999) Natural capitalism: the next industrial revolution. Boston: Little, Brown \& Co.

ICMM (2006) Maximizing value - guidance on implementing materials stewardship in the minerals and metals value chain. International Council on Mining \& Metals (ICMM), London, Retrieved from www.icmm.com

IKEA (2012) The IKEA our code of conduct - IWAY. Retrieved March 17, 2015, from http://www. ikea.com/ms/en_IE/about_ikea/our_responsibility/iway/

ISEAL (2015) ISEAL members. Retrieved March 10, 2015, from http://www.isealalliance.org/

ISWA (2002) ISWA's 10 years perspective on waste management. http://www.iswa.org/en/home/ search/

Morel S (2014) L'empreinte environnementale à l'ère de la société collaborative: de l'Analyse du Cycle de Vie comme outil expert à une instrumentation collaborative pour conduire une transition organisationnelle, École Nationale Supérieure des Mines de Paris. https://pastel.archivesouvertes.fr/tel-01152159/document

OECD (2001) OECD environmental strategy for the first decade of the 21st century. Retrieved from http://www.oecd.org/environment/indicators-modelling-outlooks/1863539.pdf

OECD (2012) Sustainable materials management - making better use of resources. http://www. oecd.org/env/waste/smm-makingbetteruseofresources.htm

Reeve (2012) The state of municipal sustainable procurement in Canada - best practices \& current trends. Retrieved from https://reeveconsulting.files.wordpress.com/2011/05/2012-state-ofmunic-sust-proc-canada.pdf

Remmen A, Jensen AA, Frydendal J (2007) Life cycle management - a buisness guide to sustainability. UNEP, http://vbn.aau.dk/files/12154798/_Final_version_for_internal_use_20070509.pdf

Salo J (2015) Beyond the brand: leaders in supply chain environmental sustainability. Retrieved March 17, 2015, from http://www.trucost.com/blog/104/beyond-the-brandleaders-in-supply-chain-environmental-sustainability

Seuring S (2004) Industrial ecology, life cycles, supply chains: differences and interrelations. Bus Strateg Environ 13(5):306-319. doi:10.1002/bse.418

Seuring S, Goldbach M (eds) (2002) Cost management in supply chains. Physica-Verlag, Heidelberg, pp 15-30

Unilever (2015) Sustainable living. Retrieved March 14, 2015, from http://www.unilever.com/ sustainable-living-2014/our-approach-to-sustainability/our-strategy/

Walmart (2015) Responsible sourcing. Retrieved March 17, 2015, from http://corporate.walmart. com/global-responsibility/ethical-sourcing/ 